\title{
Apontamentos acerca da \\ conexão repressiva entre as ditaduras brasileira echilena
}

\author{
Ananda Simões Fernandes* \\ Sílvia Simões ${ }^{* *}$
}

Este artigo tem por objetivo demonstrar a conexão repressiva entre as ditaduras brasileira e chilena a partir do golpe de Estado no Chile em 11 de setembro de 1973. Essa conexão se estabeleceu em diversos âmbitos - políticos, sociais, econômicos, militares - e envolveu as estruturas da comunidade de segurança e informação de ambos os países. Desse modo, investiga-se a atuação de diversos organismos brasileiros e chilenos na colaboração na luta contra o "inimigo interno" e o "comunismo", tais como a polícia política e a diplomacia. Essa conexão se estende até a formalização da rede maior de cooperação entre as ditaduras do Cone Sul, em novembro de 1975, que ficou conhecida como Operação Condor.

Palavras-chave: Ditadura brasileira. Ditadura chilena. Conexão repressiva.

\section{Introdução}

A Nacional do Cone Sul esta- $^{\text {s ditaduras de Segurança }}$ beleceram uma conexão repressiva internacional através da Operação Condor, fundada em 1975. Esse intercâmbio instituiu uma rede de cooperação entre si, com o propósito de interligar os sistemas repressivos e de informações entre esses países. Entretanto, o que a Operação Condor realizou foi redimensionar rela-

\footnotetext{
* Doutoranda em História/UFRGS. Historiadora do Arquivo Histórico do RS. anandasfernandes@gmail.com

** Mestre em História/UFRGS. silviasimoes73@gmail.com
} 
This article intends to demonstrate the connection between the Brazilian and Chilean repressive dictatorships since the coup in Chile on September 11 in 1973. This connection has been established in different aspects- political, social, economic, military - and involved the structures of information's and safety communities from both countries. Thereby, we investigate the performance of many Brazilian and Chilean institutions in collaboration in the fight against the "internal enemy" and "communism", such as the political police and diplomacy. This connection extends to the formalization of the largest network of cooperation between the dictatorships of the Southern Cone, in November 1975, which became known as Operation Condor.

Keywords: Brazilian dictatorship. Chilean dictatorship. Repressive connection.

ções que já existiam entre os regimes de Segurança Nacional, pois desde 1964, quando o Brasil sofreu o golpe de Estado, iniciou-se a experiência de acirramento de mecanismos regionais de coordenação repressiva. A ditadura civil-militar brasileira se constituiu, então, numa espécie de "laboratório" e também como exportadora de técnicas coercitivas no "combate à subversão".

Durante o período que ficou conhecido como "anos de chumbo" (1968-1974) no Brasil houve a promoção da política do terrorismo de Estado, decorrente da maturação de um processo que, paulatinamente, tendia ao aumento do uso da violência e da força, configurando-se como o momento de sistematização e generalização das práticas repressivas - tortura, sequestros, assassinatos e desaparecimentos. Mas, para se compreender essa escalada autoritária, é imprescindível não esquecer o "milagre econômico", que ocasionou que as camadas médias e altas da sociedade passassem a legitimar a ditadura (e logo, a repressão) e também levando à pauperização cada vez maior das camadas pobres da população brasileira. "Chumbo" e "milagre" coexistiram nesse período; as marcas dos dois ainda estão presentes na história recente brasileira.

Essas diretrizes estabelecidas também repercutiram na sua política externa. Aliando um alto patamar de repressão e de projeção de desenvolvimento econômico, a ditadura brasileira estendeu-se pelo restante do Cone Sul, interferindo na política interna de vários países e apoiando golpes con- 
trainsurgentes de Segurança Nacional, casos da Bolívia, do Uruguai e do Chile. Além disso, foi acrescentada uma apreensão aos estrategistas brasileiros: não se preocupavam somente com seu "inimigo interno" (exilados, banidos, clandestinos); agora, estavam interessados também no "inimigo interno" dos outros países do Cone Sul, dentre eles, a Unidad Popular e o governo socialista de Salvador Allende.

\section{Mortos e desaparecidos brasileiros na ditadura chilena}

A partir do dia em que o golpe de Estado foi deflagrado no Chile, em 11 de setembro de 1973, colocou-se em funcionamento um sistema voltado para a execução e desaparecimento de pessoas, embora ainda não tão estruturado como veio a ser posteriormente, com a criação ainda embrionária da Dirección de Inteligencia Nacional (DINA), em novembro desse mesmo ano. De capital importância para esse sistema foi a modificação da legislação anterior, imediatamente posterior à instalação da Junta Militar, pois as investigações de mortes violentas, antes de competência dos Tribunais de Crime, passaram em sua quase totalidade ao controle jurisdicional dos Tribunais Militares, responsáveis, agora, pelos casos com indícios de terem sido praticados por forças militares ou policiais - tais como mortes por feridas de balas, por exemplo. A consequência direta dessa nova jurisdição foi a de implementar, segundo Pascale Bonnefoy e John Dinges, um sistema que serviu não para fazer justiça, mas para ignorar as leis e encobrir os crimes: "el caos sirvió más bien al propósito de las nuevas autoridades", ${ }^{1}$ pois os próprios Tribunais, ao não investigarem os crimes, não se ajustaram

\footnotetext{
${ }^{1}$ BONNEFOY, Pascale; DINGES, John. Ejecuciones en Chile septiembre-diciembre 1973: El circuito burocrático de la muerte, textos apresentados pelo Proyecto Autopsias, desenvolvido por Archivo Chile, e que recolhe informações sobre os detidos-desaparecidos no período de 11 de setembro a 31 de dezembro de 1973, valendo-se da documentação do Cementerio General, do Segundo Juzgado Militar, do Servicio Médico Legal, do Servicio de Registro Civil, além de entrevistas com funcionários destes órgãos à época do golpe de Estado, familiares de vítimas, advogados e especialistas em direitos humanos. Disponível em: http://archivoschile.org/2012/01/ejecuciones-chile-septiembre-diciembre-1973/.
} 
à nova legalidade imposta pela Junta Militar, uma vez terem a responsabilidade de abrir sumários de ofício - independente de provocação - quando se tratasse de mortes violentas. ${ }^{2}$

Os corpos remetidos ao necrotério de Santiago estavam, em sua maioria, sob a jurisdição da II Fiscalía Militar, que contava com o general Herman Brady Roche como um de seus juízes, o qual mantinha relações estreitas com o embaixador brasileiro no Chile Antônio Castro da Câmara Canto. Brady detinha, também, os postos de Comandante de la Guarnición de Santiago e do Comando de Area Jurisdiccional de Seguridad Interior (CAJSI), este último com dependência direta de Augusto Pinochet, operando a partir do Cuartel General de la II División de Ejército, comandada, de igual modo, pelo general Brady. Como se não bastasse essa concentração de funções, este mesmo general era Jefe de la Zona en Estado de Sitio, apontando para a criação de uma hierarquia institucional que, desde o início, facilitou o ocultamento e a impunidade dos crimes cometidos.

Dois detidos brasileiros passaram por esse "circuito burocrático da morte", sendo "remetidos" pela II Fiscalía Militar para o Servicio Médico Legal (SML), onde passaram por identificações do Servicio de Registro Civil e Identificación, até chegarem ao Cementerio General de Santiago, ponto final desta trajetória. São eles Wânio José de Mattos e Nelson de Souza Kohl.

Wânio José de Mattos, militante da Vanguarda Popular Revolucionária (VPR), era capitão da Força Pública do Estado de São Paulo - atual Polícia Militar -, advogado especializado em Direito Internacional, formado pela Faculdade de Direito da Universidade de São Paulo, e foi banido para o Chile em janeiro de 1971, junto com outros 69 presos políticos por ocasião do sequestro do embaixador suíço no Brasil, Giovanni Enrico Bucher. ${ }^{3}$

\footnotetext{
${ }^{2}$ BONNEFOY, Pascale; DINGES, Johan. Op. cit. El agujero negro de las fiscalías militares. Diferentes textos fazem parte do Proyecto Autopsias, podendo ser acessados no mesmo site do artigo de apresentação - Ejecuciones en Chile septiembre-diciembre 1973.

${ }^{3}$ INSTITUTO DE ESTUDOS SOBRE A VIOLÊNCIA DO ESTADO. Comissão de Familiares de Mortos e Desaparecidos. Dossiê Ditadura: mortos e desaparecidos políticos no 124 
No Informe Rettig há a constatação de que já no dia 13 de outubro, detido no Estadio Nacional, Wânio apresentava sintomas progressivos de tifo, com constipação e vômitos, mas foi verificado que ele não poderia ser atendido pelo menos até dez dias depois, pois não havia como cuidar de todos os doentes. Em função desse quadro, seu traslado ao Hospital Militar foi solicitado ao delegado médico do Estadio Nacional, pedido este negado. Como consequência, Wânio faleceu no dia 16 de outubro de 1973, no Hospital de Campaña do Estadio Nacional, sendo atestado como causa mortis "peritonite aguda". ${ }^{4}$

No Dossiê dos Mortos e Desaparecidos Políticos no Brasil encontra-se relatado que o Centro de Informações de Segurança da Aeronáutica (CISA) fez uma comunicação - mediante Informação $N^{\circ}$ 583/DIS/COMZAE-4, de 23 de novembro de 1973 - acerca de banidos brasileiros mortos no Chile, estando o nome de Wânio na relação de nomes enviada. Isso permite que se conclua que as Forças Armadas brasileiras sabiam da sua morte desde 1973.5

Outros elementos que corroboram essa hipótese é o fato de que o Ministério de Relações Exteriores do Brasil recebeu do Centro de Informações do Exterior (CIEx), no dia 31 de dezembro de 1973, o informe 656, no qual está registrada a morte de Wânio (inclusive constando a data), estando anexo ao documento o "certificado médico de defunción (falecimento)".

O processo dos familiares de Wânio José de Mattos junto à Comissão Especial de Mortos e Desaparecidos Políticos foi indeferido, em função de não se obterem provas de que o aparato repressivo brasileiro tivesse participado da sua prisão e morte. ${ }^{6}$ Porém, há vários informes produzidos

Brasil (1964-1985). 2. ed. rev. e amp. São Paulo: Imprensa Oficial, 2009. p. 475-478.

${ }^{4}$ INFORME DE LA COMISIÓN DE VERDAD Y RECONCILIACIÓN. Informe Rettig. III Tomos. Reeditado por la Corporación Nacional de Reparación y Reconciliación. Reedición: Santiago de Chile, diciembre 1996. Volumen I - Tomo I. p. 189.

${ }^{5}$ Dossiê Ditadura: mortos e desaparecidos políticos no Brasil, op. cit., p. 475-478.

${ }^{6}$ BRASIL. Secretaria Especial dos Direitos Humanos. Comissão Especial sobre Mortos e Desaparecidos Políticos. Direito à memória e à verdade. Brasília: Secretaria Especial dos 
pelo CIEx demonstrando a espionagem que ele sofrera por parte de agentes brasileiros agindo no Chile, assim como informações que facilitaram sua prisão pelas forças policiais chilenas. Como exemplo dessa atuação de espionagem de agentes brasileiros, há o informe 159, de 27 de março de 1973, no qual se observa que um agente do CIEx teve acesso a apontamentos pessoais de Wânio José de Mattos.

Por sua vez, na Base de Dados ${ }^{7}$ desenvolvida pelo Proyecto Autopsias, que dá conta dos corpos que deram entrada no SML de Santiago no período de setembro a dezembro de 1973, encontram-se os dados que individualizam a situação de Wânio Mattos, mas que, ao mesmo tempo, permitem traçar uma visão global da repressão e o papel dos diferentes organismos que nela atuavam. Na parte da Base de Dados destinada às informações obtidas junto à documentação do SML de Santiago, constata-se que o corpo de Wânio foi remetido a este local pela II Fiscalía Militar, estando registrada sua morte no Hospital Campaña de Estadio Ncional no dia 16 de outubro de 1973, às 01h15min, devido à enfermidade: "peritonitis aguda por cancer intestino grueso". O médico que realizou a autopsia foi Alfredo Vargas. ${ }^{8}$ Seus restos foram transladados diretamente para o Cementerio General no dia 3 de novembro de 1973, sendo retirado do SML pela assistente social dessa instituição.

Nos dados preenchidos com a pesquisa feita pela equipe do Projeto, constata-se que o corpo foi identificado pelo Registro Civil, em 26 de outubro de 1973, como Arnoldo Canu Veloso; entretanto, o registro do

Direitos Humanos, 2007. p. 356-357.

${ }^{7}$ MÉRIDA, Gabriel. Proyecto Autopsias. Base de datos del SML y otras fuentes. Datos: cuerpos ingressados al Servicio Médico Legal, 1973. Disponível em: http://archivoschile. org/2011/08/base-de-datos-sml/.

${ }^{8} \mathrm{O}$ Diretor do SML era o doutor Alfredo Vargas Baeza e, devido à insuficiência de médicos para realizar as necropsias, o SML teve que recorrer a outros médicos do necrotério, como foi o caso do doutor Alfredo Vargas Kother, filho de Vargas Baeza. Apesar de se saber que os dois, juntos, realizaram 209 necropsias, não foi possível determinar o número exato de quantas foram feitas por cada um deles, porque nos registros do IML seus nomes constam como Alfredo Vargas, Alfredo Vargas K. e Alfredo Vargas B. Proyecto Autopsias: Dentro del Instituto Médico Legal (II): Autopsias sucintas. 
Cementerio General indica que foi "incinerado como indigente", ficando suas cinzas no forno crematório. Como não havia familiar para reclamar e identificar o corpo, uma vez sua esposa - também detida no Estadio Nacional - conseguir, por intermediação da Cruz Vermelha, se asilar com a filha do casal na Embaixada da França, Wânio foi cremado como NN (Ningún Nombre), situação esta apontada na pesquisa: "También hubo un docena de casos en que el Registro Civil informo la identidade de falecidos, pero asociados a un número de protocolo distinto al asignado a ese cuerpo en la morgue, o con un nombre que resultó ser incorrecto". ${ }^{9}$ Além disso, não se cumpriu a norma regulamentar do SML, que determinava que todos os cadáveres que entrassem no IML fossem fotografados, devendo essas fotos serem arquivadas para consulta eventual dos Tribunais. ${ }^{10}$

Nelson de Souza Kohl, brasileiro, militante do Partido Operário Comunista (POC), saiu do Brasil devido à perseguição política, exilando-se na Argentina, onde ficou até novembro de 1972, indo, depois, morar em Santiago do Chile, local em que trabalhou como tradutor no Instituto de Estudos Econômicos e Sociais. ${ }^{11}$ Foi sequestrado em sua residência no dia 15 de setembro de 1973 por efetivos da Fuerza Aerea de Chile, sendo executado um dia depois, em Santiago. A certificação oficial de sua morte foi obtida somente em 1993, após numerosas gestões perante organismos internacionais de Direitos Humanos, e sua família foi informada, posteriormente, que seus restos mortais foram cremados um mês depois de seu falecimento. ${ }^{12}$

\footnotetext{
${ }^{9}$ BONNEFOY, Pascale; DINGES,John. Op . cit. Registro Civil: identidades cruzadas, cuerpos sin nombre. A pesquisa assinala que nem sempre os dados do SML sobre incineração são confiáveis, pois há casos de corpos que, tendo essa anotação, foram enterrados no Patio 29 do Cementerio General.

${ }^{10}$ BONNEFOY, Pascale; DINGES, John. Op. cit. Dentro del Instituto Médico Legal (II).

${ }^{11}$ Dossiê Ditadura: mortos e desaparecidos políticos no Brasil, op. cit., p. 465-466.

${ }^{12}$ CORPORACIÓN NACIONAL DE REPARACIÓN Y RECONCILIACIÓN. Informe sobre Calificación de Víctimas de Violaciones de Derechos Humanos y de la Violencia Política. Santiago de Chile, septiembre de 1996. Capítulo Tercero - Índice Onomástico de Víctimas. A) Víctimas de Violaciones de Derechos Humanos. Parte 2. Detenidos Desaparecidos. p. 535-536.
} 
Nos dados entregues pelo Servicio Médico Legal, consta que seu cadáver foi enviado ao SML pela II Fiscalía Militar, e o local onde encontraram o corpo é "ignorado". A data do falecimento está registrada como 16 de setembro de 1976 , às $09 \mathrm{~h} 45 \mathrm{~min}$, com procedência da $8^{a}$ Comisaría. A causa externa da morte indicada nos registros é "Disparo de arma de fuego de intención no determinada", e a natureza da lesão mortal é "herida bala tóraco abdominal". O médico responsável pela necropsia foi Alfredo Vargas Baeza, diretor do SML; o corpo registra saída do SML em 26 de setembro de 1973, com translado direto para o Cementerio General. No campo destinado a "Retiro Cuerpo / Familiar", consta que isso foi feito pelo próprio SML, constituindo-se em um "Cuerpo sin entrega", denominação dada pelos pesquisadores do Projeto aos executados políticos confirmados cujos restos não foram entregues ou encontrados. ${ }^{13}$

Os registros de Nelson de Souza Kohl demonstram de modo contundente as tergiversações e arbitrariedades instauradas desde o princípio na ditadura chilena. Em primeiro lugar, como apontado pelo Proyecto Autopsias, tem-se que dos 785 corpos confiados às Fiscalías Militares, 670 são vítimas confirmadas de violações aos direitos humanos pela Comissão Rettig; dessas 785 vítimas, 755 correspondem à II Fiscalía Militar. ${ }^{14}$ Depois, apesar de os laudos das necropsias apontarem corretamente a natureza da lesão mortal, pouquíssimos indicaram se tratar de um homicídio, como era sua obrigação, determinada por lei: ${ }^{15}$ mesmo havendo ação evidente de terceiros, a causa externa é "Disparo arma de fuego de intención no determinada" numa ampla gama de casos. Por fim, o local é "Ignorado", apesar de sua procedência ser a $8^{a}$ Comisaría, que deveria precisar o local da morte, pois foi difundido que Nelson Kohl morreu em via pública devido a um enfrentamento com a polícia.

Nessa espiral de terror e violência que se seguiu à instalação do golpe civil-militar, caíram também os brasileiros Luis Carlos de Almeida e Tulio

\footnotetext{
${ }^{13}$ MÉRIDA, Gabriel, Base de Datos. Op. cit.

${ }^{14}$ BONNEFOY, Pascale; DINGES, Johan. El agujero negro de las fiscalías miliatres, op. cit. ${ }^{15}$ BONNEFOY, Pascale; DINGES, John. Dentro del Instituto Médico Legal (II), op. cit. 
Roberto Cardoso Quintiliano, ambos "cuerpo sin entrega" - executados políticos confirmados e detido-desaparecidos no Chile.

Luis Carlos de Almeida, inicialmente militante do POC, dele se desligou em fevereiro de 1970, a fim de colaborar na reconstrução da Política Operária (POLOP) com a OCML-PO - Organização de Combate Marxista-Leninista-Política Operária. Professor de Física Experimental na Universidade de São Paulo, exilou-se no Chile, passando a desenvolver essa função na legendária Universidad Técnica (UTE) de Santiago, onde iniciou contatos com o Movimiento de Izquierda Revolucionaria (MIR). Luis Carlos foi sequestrado de sua casa junto a seu amigo Luis Carlos Almeida Vieira em 14 de setembro de 1973, por efetivos de Carabineros. Conforme testemunho de Vieira, ambos foram conduzidos à Delegacia do setor de Barrancas, e daí, durante a noite, para o Estadio Nacional, local em que foram torturados e interrogados. Depois ambos foram levados pelos militares para uma das margens do rio Mapocho, onde foram obrigados a entrar na água, junto com um preso uruguaio, sendo metralhados pelas costas. ${ }^{16}$ Vieira sobreviveu porque perdeu a consciência ao ser baleado, e seu corpo foi levado pelas águas do rio, o que possibilitou que se salvasse. ${ }^{17} \mathrm{O}$ corpo de Luis Carlos de Almeida não foi encontrado, estando ele na condição de detido-desaparecido no Chile.

Tulio Roberto Cardoso Quintiliano, militante do Partido Comunista Brasileiro Revolucionário (PCBR), pediu asilo na Embaixada do Chile, viajando para Santiago em $1^{\circ}$ de outubro de 1970, junto com sua esposa. Nesta cidade, morava e trabalhava como engenheiro, sendo funcionário da Corporación de la Reforma Agraria (CORA). Sua esposa - Narcisa Beatriz Verri Whitaker - declarou que ambos foram detidos no dia 12 de setembro de 1973, às 09h:30min, por uma patrulha militar, e levados para a Escola Militar. Ela informou ao Alto Comissariado das Nações Unidas para Refugiados (ACNUR), em carta datada de 3 de outubro de 1973, que foi

\footnotetext{
${ }^{16}$ Informe sobre Calificación de Víctimas de Violaciones de Derechos Humanos y de la Violencia Política, op. cit., p. 661.

${ }^{17}$ Dossiê Ditadura: mortos e desaparecidos políticos no Brasil, op. cit., p. 463-465.
} 
liberada na mesma noite do dia 12, e que Túlio, por não ter sua documentação em ordem, foi encaminhado para o Regimiento Tacna. ${ }^{18}$

No caso de Tulio, sua morte foi investigada não pelas Fiscalias Militares, como foi o usual, pois seu caso foi aceito pela Corte de Apelaciones de Santiago, o que não impediu o ocultamento dos fatos para eximir de responsabilidades os responsáveis, deixando-os impunes: "Las gestiones realizadas por los representantes diplomáticos de su país en Chile, tampoco lograron obtener información sobre su paradero", ${ }^{19}$ sendo que o embaixador brasileiro Antônio Câmara Canto foi contatado pela mãe de Tulio e por sua esposa, a fim de que as ajudassem a encontrá-lo. Os mecanismos da impunidade funcionaram a partir do acolhimento do habeas corpus impetrado por sua esposa junto à Corte de Apelaciones de Santiago, que requereu informações à Escuela Militar, ao Ministerio de Defensa Nacional e ao Comandante do Regimiento Tacna. A Escuela Militar comunicou, oficialmente, que seu pessoal havia detido Tulio Quintiliano, transladando-o ao Regimiento Tacna após os interrogatorios.

Este fato foi negado pelo Regimiento, alegando que as pessoas que por lá passaram entre os dias 11 e 12 de setembro estavam na qualidade de "Transito al Estadio Chile", não havendo, por isso, antecedentes de sua passagem. Por seu lado, o Comandante en Jefe de la II División de Ejército, general de Brigada Herman Brady Roche, remarcou que Tulio não se encontrava detido por ordem dos Tribunais Militares, também não existindo registros de sua prisão por qualquer outra autoridade. As gestões prosseguiram até que, em 2 de janeiro de 1974, a Corte de Apelações recebeu novo informe negativo do Comandante da II Fiscalía Militar - dessa vez assinado pelo general de Brigada Sergio Arellano Starck -, e com isso denegou o pedido de habeas corpus, mesmo sem a resposta do Regimiento Tacna. Além disso, mesmo estando Tulio na condição de desaparecido, os antecedentes do caso não foram enviados para o Juzgado de Crímen competente para julgar o caso. ${ }^{20}$

\footnotetext{
${ }^{18}$ Idem, p. 461-463. O Regimiento Tacna foi um centro de detenção transitório, assim como foram o Ministério da Defesa e a Escola Militar.

${ }^{19}$ Informe Rettig, Volumen I - Tomo I, op. cit., p. 125.

${ }^{20}$ Dados sobre as gestões judiciais em MEMORIA VIVA - Archivo Digital de las Violacio- 


\section{Conexão repressiva: vigilânciae monitoramento}

Enquanto no Chile cidadãos de diversas nacionalidades eram perseguidos e mortos na investida contra os estrangeiros, os órgãos de repressão e inteligência do Brasil monitoravam tanto brasileiros quanto chilenos, ante o perigo de sua infiltração no território nacional, como consta no INFORME N 006 do Departamento de Polícia Federal de Bagé, datado de 16 de novembro de 1973. Nele, comprova-se que Isidoro Antonio Vianna Gutierres "teria sido ferido na Revolução chilena, e que o mesmo teria atravessado a fronteira do mesmo país, em direção ao Brasil ou Uruguai". Aponta também que Isidoro é natural de Uruguaiana, está desaparecido do Brasil desde 1964, e que possui um contato no Uruguai, informando que ele "costuma entrar pelas fronteiras de Bagé ou Livramento, usando disfarces (barba e peruca)". ${ }^{21}$

Em 30 de outubro de 1973, o DOPS/RS - Divisão de Busca e Coleta de Informações -, expede a ORDEM DE BUSCA N ${ }^{\circ} 823 / 73$, cujo Assunto é: Infiltração do PC Chileno no Brasil:

\section{DADOS CONHECIDOS}

1.1 - Encontram-se em território brasileiro, fugidos do CHILE, comunistas chilenos e brasileiros que lá estavam asilados. Os comunistas chilenos eram, no CHILE, da categoria de quadros dirigentes.

1.2 - O homizio em solo brasileiro tem dupla finalidade:

nes de los Derechos Humanos de la Dictadura Militar en Chile (1973-1990). Posteriormente, os antecedentes antropomórficos de Tulio Roberto Quintiliano Cardoso foram anexados à causa acolhida pelo $22^{\circ}$ Juzgado del Crimen de Santiago, pelo delito de inumação ilegal no Patio 29 do Cementerio General, de pessoas não identificadas mortas entre setembro e dezembro de 1973. Disponível em: http://www.memoriaviva.com/Desaparecidos/D-Q/tulio_roberto_quintiliano_cardos. Até o presente momento, nenhuma das 55 identificações ocorridas no Patio 29 corresponde às ossamentas de Túlio Quintiliano.

${ }^{21}$ ARQUIVO HISTÓRICO DO RIO GRANDE DO SUL. Acervo da Luta Contra a Ditadura. Ministério da Justiça / Departamento de Polícia Federal / Divisão de Bagé / Informe No 006/73/SI/DPF/BAGE. CX - 1.2.2007.25.7. 
1.2.1 - a fuga à ação da Junta Militar Chilena;

1.2.2 - formação de uma brigada nacional chilena no exterior.

1.3 - Será feito junto ao PCB uma campanha financeira, entre amigos e aliados, visando à manutenção e estadia desses elementos.

1.4 - Está previsto, também, a formação de francoatiradores ligados à Brigada Nacional, bem como a criação de campos de treinamentos de guerrilheiros, sendo que as áreas preferências serão nas fronteiras Brasil/Argentina e Brasil/Peru.

1.5 - A orientação geral do programa está a cargo do Partido Comunista Argentino.

1.6 - Será também editado um jornal clandestino cuja matéria versará sobre acontecimentos no CHILE, com técnica de propagando visando à retomada do poder $[\ldots] .{ }^{22}$

No Chile houve detidos-desaparecidos brasileiros ainda depois da fase massiva de prisões e assasinatos, característica dos três primeiros meses posteriores ao golpe de setembro de 1973. É o caso de Jane Vanini - militante da Ação Libertadora Nacional (ALN) e, posteriormente, do Movimento de Libertação Popular (MOLIPO), no Brasil -, inserindo-se em outra lógica e forma de organização do aparato repressivo, pois sua execução ocorreu no dia 6 de dezembro de 1974, por efetivos da Marinha.

Conforme relato da Corporación Nacional de Reparación y Reconciliación, Jane Vanini ingressou no Chile em 1971, como exilada política da ditadura brasileira, passando a viver com o jornalista chileno e dirigente do MIR José "Pepe" Carrasco Tapia. ${ }^{23}$ Devido à perseguição, nesse ano,

\footnotetext{
${ }^{22}$ ARQUIVO HISTÓRICO DO RIO GRANDE DO SUL. Acervo da Luta contra a Ditadura. DOPS / Divisão de Busca e Coleta de Informações / OB No 823/73/DOPS/RS. CX -1.2 .2007 .25 .7 .

${ }^{23}$ Pepe Carrasco foi detido no dia 5 de dezembro e levado para a Base Naval de Talcahuano, onde foi torturado. A seguir, foi transladado a Villa Grimaldi e Cuatro Álamos, recintos de detenção clandestina da DINA, em Santiago. Após, foi enviado ao campo de prisioneiros de Puchuncaví, saindo da prisão em 1976, e se exilando no México em 1977. Regressando ao Chile em 1984, foi executado em um operativo de vingança na madrugada do dia 8 de setembro de 1986, devido ao atentado contra o ditador Augusto Pinochet.
} 
aos dirigentes dessa organização política, objetivando capturar seu líder máximo, Miguel Enríquez, ${ }^{24}$ o casal optou por viver na clandestinidade na cidade de Concepción, onde tinham ordens de reorganizar o partido e seus quadros. Consta que o apartamento onde Jane morava com seu companheiro foi cercado no dia 6 de dezembro, quando ela foi ordenada a se entregar, resistindo à voz de prisão. Devido a isso, no local se produziu um tiroteio no qual ela morreu: ${ }^{25}$ essa versão oficial, proporcionada pela II Zona Naval de Talcahuano, foi publicada nos jornais El Sur e Diario Color de Concepción, em 8 de dezembro de 1974, afirmando que um grupo de "terroristas" havia enfrentado os soldados da Marinha e policiais, tendo Jane Vanini se suicidado. ${ }^{26}$

Conforme dados do Archivos CEME, posteriormente apuraram-se as reais circunstâncias de sua morte, constatando-se que Jane foi ferida e presa nesse enfrentamento por efetivos de Ancla II, Serviço de Inteligência da Marinha de Talcahuano. Conduzida ferida na madrugada de 6 de dezembro à Base Naval desse local, ${ }^{27}$ foi assassinada no dia seguinte, no Hospital Naval de la Armada Nacional. Jane foi enterrada como NN no dia 10 de dezembro de 1974, no Cementerio $N^{o} 2$ desta cidade. ${ }^{28}$

De fato, no ano de 1974 já existia um modelo mais permanente de repressão, estando esta melhor estruturada em sua planificação e logística. Conforme Mario Amorós, a necessidade de estruturação da repressão, a

\footnotetext{
${ }^{24}$ Miguel Enríquez, executado em 5 de outubro de 1974, no operativo conhecido como Calle Santa Fe, por agentes da DINA.

${ }^{25}$ Informe sobre Calificación de Víctimas de Violaciones de Derechos Humanos y de la Violencia Política, op. cit., p. 947.

${ }^{26}$ Dossiê Ditadura: mortos e desaparecidos políticos no Brasil, op. cit., p. 597-599.

${ }^{27}$ A Base Naval de Talcahuano ou Base "El Morro" funcionou como local de detenção e tortura após o golpe de 11 de setembro até o ano de 1975, e foi o principal recinto usado pelo Servicio de Inteligencia Regional (SIRE) de Concepción. O SIRE contava com oficiais da Marinha e do Exército entre seus comandos, também havendo uma participação importante de membros de Carabineros e Servicio de Investigaciones.

${ }^{28}$ Centro de Estudios Miguel Enríquez - CEME. Dossiê Jane Vanini. Disponível em: http:// www.archivochile.com/Memorial/caidos_mir/V/vanini_capozi_jane.pdf.
} 
fim de exterminar urgentemente toda e qualquer oposição ao novo regime, foi apontada pelo general Manuel Contreras já no final do mês de setembro de 1973, quando ele afirmou, em reunião do Estado Maior de Defesa Nacional, sobre a necessidade das Forças Armadas destinarem seus melhores homens para cumprir essa missão. Em novembro deste mesmo ano, Augusto Pinochet ordenou-lhe a confecção de um projeto para organizar a inteligência nacional, que foi aprovado com o nome de Comisión DINA, tendo como seu responsável direto Manuel Contreras. Com isso, o general pôde contar com os efetivos selecionados das Forças Armadas e Carabineros, que ficariam sob seu comando exclusivo, e que foram treinados até o final de fevereiro de 1974 no Regimiento de Tejas Verdes, - então sob seu comando -, para "combater a subversão". Com o envio do Memorando de 5 de janeiro de 1974 a todas as unidades das Forças Armadas, perfilou-se de modo ainda mais acabado o que viria a ser a coordenação repressiva, pois a DINA foi criada como órgão de assessoria para Segurança Interior e Exterior do Estado, devendo sua ações, neste momento, permanecerem absolutamente secretas. Com o Decreto Ley No 521, de 18 de junho de 1974, ela institucionalizou-se formalmente, estando subordinada exclusivamente ao Comandante da Junta Militar, e logo Presidente da República, Augusto Pinochet. A DINA, como disse o ditador, era o braço executivo para as ações de Segurança Nacional. ${ }^{29}$

Essa estruturação conferida à DINA será crucial para o progressivo aumento de seu poder, com a elaboração de diferentes redes de atuação que não se limitavam exclusivamente à repressão interna, como no caso da criação, em abril de 1974, de seu Departamento Exterior, contando com agentes em vários países. Dentre suas missões principais, estavam a de neutralizar os "inimigos" da ditadura e exercer controle sobre os funcionários designados para atuarem nas missões diplomáticas chilenas no exterior, ${ }^{30}$ tanto propor-

\footnotetext{
${ }^{29}$ AMORÓS, Mario. La DINA: el puño de Pinochet. Ponencia presentada en el Congreso Internacional de Americanistas, celebrado em julio de 2009 en México DF. Disponível em: http://www.archivochile.com/Ideas_Autores/html/amoros_m.html.

${ }^{30}$ CEME - Centro de Estudios Miguel Enríquez. História de la Creación de la DINA. Disponível em: http://www.archivochile.com/Dictadura_militar/org_repre/DMorgrepre0014.pdf. 
cionando como obtendo dessa rede diplomática informações sobre os mais variados temas, desde antecedentes de pessoas até reuniões, publicações e denúncias feitas no exterior sobre as ações da ditadura no Chile. Possuindo serviços de Inteligência e Contra Inteligência, no ano de 1975 somou-se oficialmente ao Departamento Exterior o "Condor", unidade responsável pela conexão repressiva extraterritorial das ditaduras do Cone Sul.

De fundamental importância para os operativos da DINA foi o Departamento de Análise, voltado para os arquivos e análise exterior, assessorando, também, o Departamento Exterior. Outro Departamento destacado no auxílio do Departamento Exterior, que cumprirá um papel relevante para a conexão repressiva com as ditaduras vizinhas, foi o de Operações Psicológicas, formado pelas subunidades de "Propaganda e Guerra Psicológica", "Imprensa" e "Relações Públicas". Há a formação de uma extensa e variada rede repressiva, envolvendo desde instituições governamentais e aparatos de Segurança oficiais até dispositivos repressivos clandestinos para obter informações - em centros de detenção secretos e ilegais, valendo-se de torturas e desaparecimentos forçados -, contando com a infraestrutura legal proporcionada pelo Estado. Ou seja, como ressalta Melissa Slatman, "una acumulación en las experiencias y que cada nueva experiencia repasó las anteriores, las adaptó y las desarrolló". ${ }^{31}$

\section{Adiplomacia a serviço da conexão repressiva}

A ditadura brasileira auxiliou os golpistas não somente nos campos político, econômico e repressivo, ${ }^{32}$ mas também em ações diplomáticas, de

\footnotetext{
${ }^{31}$ SLATMAN, Melisa. Terrorismo de Estado y Exilio: hipótesis exploratorias para una comparación entre los casos chileno y argentino. Jornadas de Trabajo Exilios Políticos del Cono Sur en el Siglo XX, La Plata, 26-28 sep. 2012. Disponível em: http://jornadasexilios.fahce. unlp.edu.ar.
}

${ }^{32}$ Ver: PADRÓS, Enrique Serra; SIMÕES, Sílvia. A ditadura brasileira e o golpe de Estado chileno. Outros Tempos - Pesquisa em Foco, Maranhão, v. 10, n. 16, 2013. p. 233-261. Disponível em: http://www.outrostempos.uema.br/OJS/index.php/outros_tempos_uema/ 
propaganda e espionagem, entremeando informações em campos variados, que iam desde o monitoramento e combate aos subversivos e vigilância de Embaixadas até a disposição para influenciar ou distender pressões externas exercidas sobre a ditadura chilena. Isto é, havia formas mais visíveis ou mais clandestinas de visibilidade, e a cooperação brasileira se insere nesta última.

Um exemplo disso é o denominado Plan de Operaciones Epsilon, ampla ação conjunta interministerial chilena com suas forças repressivas, desenhado e assinado, em junho de 1975, pelo Diretor da DINA, Manuel Contreras Sepúlveda, que tinha, como objetivo geral "realizar una campaña de acción psicológica abierta y clandestina", distribuindo, para tal, "misiones" aos Ministerios de Relaciones Exteriores, Dirección Nacional de Comunicación Social e à Dirección de Deportes de Estado. Esta última ficou encarregada de organizar eventos desportivos importantes, a serem realizados no Estadio Nacional, e que "aseguren una gran asistencia de público. Presentación de la Selección Nacional de futbol con la de Brasil, etc." ${ }^{33}$ Nota-se que se contava com o Brasil como um aliado que poderia intervir até mesmo nas campanhas internas do Chile, auxiliando na formação de uma imagem positiva desse país frente às pressões internacionais de organizações e organismos de direitos humanos.

Concomitante às reuniões de planejamento e execução do Plan Epsilon, realizava-se a Operación Colombo ou, como é também chamada, a Lista de los 119, que teve como objetivo principal fazer frente às denúncias da comunidade nacional e internacional sobre o destino de chilenos detidos pelos serviços de segurança neste país e que se encontravam desaparecidos. A imprensa chilena divulgou, em duas listas separadas, nos dias 23 e 24 de julho de 1975, o nome completo de 119 pessoas, todas "presuntamente" desaparecidas, que teriam se eliminado entre si em países estrangeiros, especialmente na Argentina. Essas listas de nomes provieram, originalmente,

article/view/284

${ }^{33}$ REPÚBLICA DE CHILE. Ministerio del Interior (S) No 2F248. OBJ: Campaña psicológica en el exterior ante la visita de la Comisión de Derechos Humanos. Santiago, 13 jun. 1975 / Dirección de Inteligencia Nacional. 091200. Jun. 1975. Plan de Operaciones Epsilon. 
da revista argentina Lea, que publicou, em 15 de julho, os nomes de 60 “extremistas", seguida pelo jornal O Dia, de Curitiba, que publicou, em 17 de julho, os nomes de 59 chilenos que teriam morrido nas mãos de efetivos argentinos em enfrentamentos armados.

A Operación Colombo ganhou repercussões internacionais, levando à abertura de investigações acerca da veracidade das informações constantes nos periódicos. No Ofício No 430 tarjado como SECRETO, de 24 de outubro de 1975, tendo por objeto "Remite últimos antecedentes sobre publicaciones "LEA" de Buenos Aires y "NOVO DIA" de Curitiba, en relación extremistas chilenos fallecidos o heridos", o ministro de Relações Exteriores, Patricio Carvajal Prado, enviou, para o ministro do Interior, informações recopiladas pela Chancelaria, dentre elas: "Antecedentes remitidos por la Embajada de Chile en Brasilia". Neste ofício comunicou que colocou à disposição o Adido Cultural e de Imprensa - Carlos Sepúlveda - a fim de viajar para Curitiba com o propósito de entrar em contato com Almir Lara, diretor-proprietário da gazeta Novo Dia. A seguir, Carvajal Prado relatou que aproveitou a oportunidade do cônsul honorário do Chile - Armando Roa - estar no Rio de Janeiro, visto que este, além do mais, era correspondente do Novo Dia. Roa informou ao cônsul ser amigo de Almir Lara, e que este havia lhe dito que a publicação tinha sido enviada do México pela agência FONEL, a mesma fonte informativa da Revista LEA. ${ }^{34}$

Tanto o jornal brasileiro quanto a revista argentina continuaram sendo mencionados nas correspondências entre os Ministérios do Interior e da Defesa e dos órgãos de segurança nos anos subsequentes, corroborando esses dados perante organismos internacionais que solicitavam às Embaixadas do Chile, em seus respectivos países, informações sobre essas pessoas. A título de exemplo, tem-se o Ofício Reservado $\mathrm{N}^{\circ} 237$, de 31 de agosto de 1977, do Ministério de Relações Exteriores, enviado para o Departamento Confidencial do Ministério do Interior, referente às solicitações feitas pelas Embaixadas do Chile em Washington e Londres sobre ${ }^{34}$ REPÚBLICA DE CHILE. Ministerio de Relaciones Exteriores. RR. EE. (SECREDER)
RES. N ${ }^{\circ}$ 430. Santiago, 24 oct. 1975. 
“Antecedentes de personas supuestamente desaparecidas". Entre os nomes consultados, constam oito dos publicados pela revista Lea, e cinco pelo jornal $O$ Dia, dados esses que são usados para explicar a situação dessas pessoas: "[...] Espinoza Pozo, Modesto: citado en la nómina publicada por el Diario 'O’Dia”,; “Andreoli Bravo, María Angélica: el Diario ‘O'Dia', de Curitiba, Brasil, informa que habría fallecido en un enfrentamento ocurrido en Agentina [...]", ${ }^{35}$ prolongando no tempo a falsidade acerca das condições de suas mortes em centros de detenções clandestinos no Chile.

O Ofício $\mathrm{N}^{\circ} 16831$, de 2 de setembro de 1975, tem como assunto as "Actividades realizadas pelo Ministerio de Relaciones Exteriores desde el 11 de septiembre de 1973", enviando um resumo das principais ações desenvolvidas nos diversos países que possuem representação diplomática chilena. Após realçar que os países "marxistas" tiveram como reação imediata ao "Pronunciamento Militar" a interrupção imediata entre suas relações com o Chile, e que o Supremo Governo manifestou, desde o dia 11 de setembro, a intenção de manter relações com todos os países, qualquer que fosse sua inspiração ideológica - excetuando-se Cuba, Coreia do Norte e Camboja -, procede-se à análise das ações mais destacadas por áreas, e a primeira delas destina-se à América Latina, onde o Chile obteve, no conjunto geral, "un notable mejoramiento... apreciándose un considerable y provechoso acercamiento con los países del área, muchos de ellos gravemente distanciados por el gobierno anterior". No que toca à análise individual do Brasil, o Ministro de las Relaciones Exteriores relata o seguinte para o seu par da Secretaria General de Gobierno:

BRASIL: Se han incrementado las relaciones tanto diplomáticas cuanto culturales y comerciales con los Estados Unidos del Brasil. Se han intercambiado Misiones de alto nivel, iniciadas con ocasión de la visita a ese país de S. E. el Presidente de la República.

El Sr. Ministro Director de la Oficina de Planificación Nacional visitó Brasilia y Río de Janeiro, a fines del año pasado, invitado por su congénere brasileño.

\footnotetext{
${ }^{35}$ REPÚBLICA DE CHILE. Ministerio de Relaciones Exteriores. RR. EE. (SECREDER) RES. N ${ }^{\circ}$ 237. Santiago, 31 ago. 1977.
} 
El Sr. Sergio Arellano, Jefe del Estado Mayor General de las Fuerzas Armadas, cumplió igualmente una visita profesional a Brasil con óptimos resultados.

Se estudia en la actualidad la forma de incentivar los intercambios comerciales con ese país. ${ }^{36}$

Como salientam Dorat Guerra e Weibel Barahona, as operações exteriores e interiores da ditadura e de sua polícia secreta não se resumiam à repressão física interna e externa dos "inimigos", pois havia a cooperação diplomática, análises de Inteligência e coordenação, bem como campanhas de guerra psicológica: "Los equipos represivos no solo estuvieron abocados al horror de los flagelos, sino que también a la acción política y diplomática, como parte de un todo harmónico para los militares desde los primeiros años del régimen". ${ }^{37}$ Esses elementos apontados por Guerra e Barahona foram compartilhados no marco do Plan Condor - denominado também, nas correspondências oficiais, de Plan de Informaciones en el Exterior. Com isso, situa-se o Plan Condor como um braço executivo do Departamento Exterior da DINA que se vinculava a diversas instituições da República chilena, mas também, por extensão, às demais ditaduras do Cone Sul. A abordagem, por isso, é a de um processo determinado pela acumulação de iniciativas, experiências e trocas para o desenvolvimento da sistematização da repressão. Ou seja, como aponta Slatman, a dinâmica de interação entre as partes produz fenômenos históricos que podem ser lidos somente em escala transnacional no espaço regional, ${ }^{38}$ e é nesse ponto que se podem situar as coordenações repressivas, como a Operação Condor.

A "Reunión de Trabajo de Inteligencia Nacional", realizada em Santiago do Chile entre os dias 25 de novembro e $1^{\circ}$ de dezembro de 1975 , criou formalmente a conexão repressiva entre os países do Cone Sul, de-

${ }^{36}$ REPÚBLICA DE CHILE. Ministerio de Relaciones Exteriores. RR. EE. (SUBSEC) ORD. No 16831. Santiago, 2 sep. 1975.

${ }^{37}$ DORAT GUERRA, Carlos; WEIBEL BARAHONA, Mauricio. Asociación ilícita: los archivos secretos de la dictadura. Santiago de Chile: Ceibo, 2012. p. 100-101.

${ }^{38}$ SLATMAN, Melisa. Op. cit., p. 3. 
nominada Operação Condor. Manuel Contreras, assinalando a Francisco Brites - Chefe da polícia do Paraguai - que a reunião teria caráter estritamente secreto, expõe o objetivo principal do encontro, que é o de que “esta Reunión pueda ser la base de una excelente coordinación y un mejor accionar en beneficio de la Seguridad Nacional de nuestros respectivos países". ${ }^{39}$ Participaram deste encontro, além do Chile, a Argentina, Bolívia, Paraguai, Uruguai e Brasil, país esse que, como salienta Enrique Serra Padrós, mesmo persistindo na negação de qualquer tipo de envolvimento e participação nesse esquema regional, teve os nomes de seus delegados perante à Reunião divulgados pelo jornalista brasileiro Luis Cláudio Cunha: o coronel Flávio de Marco e o major Thaumaturgo Sotero Vaz, ambos com participação destacada na campanha do Araguaia. Este mesmo autor ressalta a informação de Stella Calloni sobre o fato de que nesta Reunião foi confirmada a permissão de troca de prisioneiros entre os serviços de inteligência e a designação dos adidos militares das respectivas Embaixadas como elementos de ligação. ${ }^{40}$

A participação das forças repressivas junto às Missões Diplomáticas no exterior foi um ponto bastante enfatizado no Plan Condor, e o cumprimento desta decisão foi motivo de preocupação constante nos anos posteriores. Embora o Brasil não seja signatário no documento de criação desta rede de conexão repressiva, e negue sua ciência, envolvimento ou participação, as correspondências interministeriais ou com as forças repressivas levam a conclusões parcialmente diferentes destas assertivas. Do mesmo modo, demonstram a intensa cooperação e ação diplomática entre os países signatários ou não da Reunião efetuada em Santiago do Chile.

\footnotetext{
${ }^{39}$ Museo de la Memoria y Derechos Humanos - Archivo de Fondos y Collecciones - CL MMDH 00000094-000002-000001 - Santiago, oct. 1975. Disponível em: http://www.archivomuseodelamemoria.cl:8080/index.php/67687;isad.

${ }^{40}$ PADRÓS, Enrique Serra. Conexão Repressiva Internacional: o Rio Grande do Sul e o Brasil na rota do Condor. In: PADRÓS, Enrique Serra; BARBOSA, Vânia M.; LOPEZ, Vanessa Albertinence; FERNANDES, Ananda S. (orgs.). A ditadura de Segurança Nacional no Rio Grande do Sul (1964-1985): história e memória. v. 3. 2a ed. rev. e amp. Porto Alegre: Corag, 2010. p. 59-60.
} 
$\mathrm{Na}$ “Acta de Clausura de la Primera Reunión Interamericana de Inteligencia Nacional', datada de 25 de novembro de 1975, tendo por signatários Argentina, Bolívia, Chile, Uruguai e Paraguai, há uma série de recomendações para as suas ações futuras, como contatos bilaterais ou multilaterais para intercâmbio de informação subversiva e a criação de um escritório de Coordenação para prover os antecedentes de pessoas e organizações conectadas com a subversão. Aponta-se que o sistema de Coordenação se realize mediante três etapas, sendo que na primeira delas, no Parágrafo 5, letra "g", recomenda-se "la habilitación en las Embajadas de nuestros países, la presencia de personal de Inteligencia Nacional o similares, para enlaces directos y personales, plenamente acreditados ante los Servicios". No parágrafo 8 , letra "b", recomenda-se expressamente que "la inclusión de cualquier otro país al Sistema CONDOR, deberá contar con la aprovación del total de los países participantes a la Primera Conferencia". ${ }^{41}$

No Ofício Secreto No 300733, de 21 de fevereiro de 1978, enviado pela Central Nacional de Informaciones ${ }^{42}$ para o ministro de Relações Exteriores, o assunto em questão é "Propone a Suboficiales como Secretarios Civiles del Consejo Administrativo de Embajadas que indica", onde Odlanier Mena, Diretor da Central Nacional de Inteligencia (CNI), esclarece que destinou, em Comissão de Serviço, pessoal de Oficiais e Quadro Permanente das Forças Armadas, assim como pessoal contratado de Carabineros, para prestar assessoria em funções específicas nas Embaixadas do Chile no estrangeiro, propondo ao Ministro de Relações Exteriores os nomes dos Oficiais-Chefes que desempenharão estas funções nas Embaixadas do Peru, Bolívia e Argentina. Mena esclarece que a CNI está interessada em manter e destinar Oficiais das Forças Armadas, previamente selecionados, para prestar assessoria técnica aos Agregados Civis nas Embaixadas do

\footnotetext{
${ }^{41}$ Museo de la Memoria y Derechos Humanos - Archivo de Fondos y Collecciones - CL MMDH 00000031-000012-000019. Disponível em: http:/www.archivomuseodelamemoria.cl:8080/index.php/90834;isad?sf_culture=en.

${ }^{42}$ A CNI, subordinada ao Ministério do Interior, foi criada em 13 de agosto de 1977 pelo Decreto Ley $\mathrm{N}^{\circ} 1878$, para substituir a DINA, continuando com o trabalho repressivo de sua antecessora.
} 
Chile, a fim de dar cumprimento ao Plan de Informaciones en el Exterior, nomenclatura essa usada para designar a Operação Condor. ${ }^{43}$

Por sua vez, Enrique Valdes Puga, vice-ministro de Relações Exteriores do Chile, solicita ao Diretor da CNI, em 17 de março de 1978, que lhe envie um "ejemplar del Plan Condor" com a maior brevidade possível. Seu pedido está baseado em conversas anteriores sobre a necessidade de normalizar a situação do envio de Oficiais da CNI ou Civis, como Conselheiros Administrativos, para diferentes representações diplomáticas do Chile no exterior. Além disso, Valdes Puga solicita que o diretor da CNI ratifique sobre o conhecimento do Plan Condor pelo Ministério das Relações Exteriores do Peru. A esse respeito, pode-se inferir que, como a Embaixada deste país irá receber assessoramento de quadros de Oficiais das Forças Armadas, conforme mencionado por Odlanier Mena no Ofício de 21 de fevereiro, e o Peru não consta como país signatário da Primera Reunión Interamericana de Inteligencia Nacional, há a preocupação quanto ao alcance de informações que este país possui sobre a conexão repressiva, visto isto estar expresso nas recomendações acerca da entrada de outros países no "Sistema Condor".

Em 3 de abril de 1978, mediante o Ofício Secreto No 201621, enviado ao Ministro das Relações Exteriores por Odlanier Mena, em sua condição de Diretor da CNI, o assunto tratado é "Propone Oficial Jefe y SOF [Suboficial] a la Embajada de Chile en Brasilia, Brasil", tomando por Referência para tratar deste assunto o "Plan de Informaciones en el Exterior (CONDOR)". Mena informa que, conforme este Plan, a CNI está interessada em manter Oficiais e Pessoal que reúnam qualidades especiais de idoneidade para ocuparem os postos de Agregado Civil e Secretário da Embaixada do Chile em Brasília. Para tal designa, a fim de cumprir estas funções, o tenente-coronel Guillermo Eduardo Pavez Muñoz e o Suboficial Leon Carol Gonzalez Cerda, substituindo o tenente-coronel Enrique Cowell Mansilla e o $2^{\circ}$ Sargento Carlos Marin Castro, respectivamente. Ao final da corres-

\footnotetext{
${ }^{43}$ REPÚBLICA DE CHILE. Central Nacional de Informaciones. CNI. (S) Nº N - 300733 / M. RR. EE 1909. Santiago, 21 fev. 1978.
} 
pondência, Mena ressalva que: "Se hace presente a US. que este reemplazo ha sido informado al Servicio Nacional de Informaciones de Brasil, de acuerdo a lo estipulado en el Plan CONDOR". ${ }^{44}$

Tendo em vista que o fim do prazo da Missão desses dois funcionários na Embaixada do Chile em Brasília se dará em 31 de março de 1979, o Diretor Nacional de Informações, Odlanier Mena, escreve ao ministro de Relações Exteriores, em 02 de março de 1979, o Ofício Secreto № 205193, no qual "Propone Oficial Jefe y SOM. a la Embajada de Chile en Brasilia, Brasil", tendo por Referência para essa ação o "Plan Condor". Conforme escreve Mena, "esta Dirección está empeñada en continuar manteniendo relaciones a este nivel con la República Federativa del Brasil", razão pela qual designa o coronel (E) Sergio Hernan Osorio Saavedra, como Conselheiro Administrativo, e o Oficial Sênior (C) Joaquim Muñoz Vallejos como Secretário da Embaixada do Chile em Brasília. Novamente há a explicação de que o Serviço Nacional de Informações do Brasil foi comunicado desta substituição, de acordo ao estipulado no Plan CONDOR. ${ }^{45}$

Por outro lado, a preocupação do vice-ministro de Relações Exteriores, Enrique Valdes Puga, quanto à situação do Peru no Plan Condor é respondida pelo coronel Jeronimo L. Pantoja Henriquez, Chefe do Estado Maior da C.N.I., mediante o Ofício Secreto No 201755, de 10 de abril de 1978. Nele, além de remeter cópia da Acta de Clausura de la Primera Reunión Interamericana de Inteligencia Nacional, salientando ao vice-ministro a recomendação feita neste documento de habilitar pessoal da Inteligência Nacional junto às Embaixadas, a $\mathrm{CNI}$ informa que, conforme estipulado na Acta de Clausura, o Diretor de Inteligência do Peru telefonou para o Diretor da CNI - Odlanier Mena - informando-lhe que não havia inconvenientes para a designação do Representante do Chile em Lima, Peru. Além disso, Pantoja esclarece que o próprio Conselheiro da Embaixada

\footnotetext{
${ }^{44}$ REPÚBLICA DE CHILE. Central Nacional de Informaciones. CNI. (S) D No 201621 / M. RR. EE. Santiago, 3 abr. 1978.

${ }^{45}$ REPÚBLICA DE CHILE. Central Nacional de Informaciones. CNI. (S) D No 205193 / M. RR. EE. Santiago, 2 mar. 1979.
} 
do Peru no Chile - que é a pessoa, segundo ele, que trata dos assuntos do Condor - comunicou a conformidade do Peru com esta ação. Como se não bastasse, acrescenta que esta mesma informação chegou através do Sistema Condor, via Buenos Aires, Argentina, país este que faz as vezes de Secretaria da Comunidade. ${ }^{46}$

Menciona-se, por fim, o Ofício Secreto $\mathrm{N}^{\mathrm{o}} 70$, de 09 de agosto de 1979, no qual o ministro de Relações Exteriores - Hernan Cubillos Sallato - escreve com preocupação a Odlanier Mena: "En vista de la creciente ola de ataques que provienen desde el exterior, el Ministerio estima indispensable entregar a nuestras Misiones Diplomáticas una información completa e esclarecedora acerca del 'Plan CONDOR"',47

Em um momento de intensa campanha internacional contra a ditadura chilena, especialmente após o achado dos restos mortais de 15 detido-desaparecidos nas minas de cal da localidade de Lonquén, em dezembro de 1978, urge afrontar os ataques contra a imagem do Chile no exterior, sendo crucial o papel desempenhado pelas Missões Diplomáticas, cujas ações foram tão bem delineadas no Plan Condor.

Também neste ano de 1978, ganhou repercussão internacional, especialmente no Le Monde, o encerramento do sumário do processo instruído pelo homicídio de Juan Rene Muñoz Alarcón, cuja denúncia ante a Corte Suprema foi feita em 17 de novembro de 1977, pelo Vigário Episcopal Cristian Precht Bañados, da Vicaría de la Solidaridad.

Muñoz Alarcón, morto em 24 de outubro de 1977 com feridas múltiplas de bala, havia sido membro do Partido Socialista e, posteriormente, colaborador dos serviços de segurança da ditadura, atividades essas que abandonou no ano de 1977, quando prestou seu testemunho à Vicaría de la Solidaridad. Neste, declarou ter sido o "encapuchado" do Estadio Na-

\footnotetext{
${ }^{46}$ Museo de la Memoria y Derechos Humanos - Archivo de Fondos y Collecciones - CL MMDH 00000031-000012-000019. Disponível em: http://www.archivomuseodelamemoria.cl:8080/index.php/90834;isad?sf_culture $=$ en.

${ }^{47}$ REPÚBLICA DE CHILE. Ministerio de Relaciones Exteriores. RR. EE. (DIBILAT) SECRETO No 70. Santiago, 9 ago. 1979. 
cional, quando andava pelas arquibancadas reconhecendo militantes de esquerda, que eram separados dos demais detidos, ${ }^{48}$ além de denunciar acerca da localização e práticas repressivas nos centros de detenção clandestinos; organismos responsáveis pelos desaparecimentos de prisioneiros; identidade de repressores, tanto militares quanto civis; informações sobre os detido-desaparecidos, fazendo inclusive uma lista de nomes dos que eram procurados e ainda estavam vivos.

Odlanier Mena envia, em 2 de agosto de 1978, mediante o Ofício Reservado $\mathrm{N}^{\mathrm{o}} \mathrm{G}-203616$, extenso Memorando explicativo ao ministro de Relações Exteriores, detalhando minuciosamente os fatos, e "provando" sua falsidade, ponto por ponto, visando fornecer todos os antecedentes para que a Embaixada do Chile em Paris possa afrontar as denúncias praticadas no exterior. Junto a este documento, envia fotocópia da denúncia feita por Muñoz Alarcón, onde se encontra a seguinte informação acerca da conexão repressiva transnacional:

[...] Existe en este momento en el país un escuadrón de la muerte, comandado por el capitán Rolando Larenas, oficial de Artillería, para que lo ubiquen posteriormente. Este hombre mantiene contacto con los servicios de inteligencia brasileños, argentinos y uruguayos, quienes actúan indiscriminadamente dentro del país. El 50\% de los vehículos con patente argentina que ingresan por los diferentes pasos, ingresan como turistas, siendo ellos, en realidad, vehículos del aparato de inteligencia argentino que trabajan en equipo con los servicios de inteligencia nuestra. La labor de estos servicios es cazar al hombre en el exterior y traerlo para acá y aquí se termina: se intercambian prisioneros. Todo esto permitido y avalado por el Presidente de la República, que es el jefe directo de todo ese asunto. Porque el Jefe de la DINA le corresponde personalmente a él. El Ministerio del Interior, los Tribunales de Justicia no cuentan ni tienen ninguna injerencia sobre estos servicios. ${ }^{49}$

\footnotetext{
${ }^{48}$ Informe Rettig, Volumen I, Tomo I, op. cit., p. 115. Ainda hoje há dúvidas de que o "encapuchado del Estadio Nacional" tenha sido somente uma pessoa, no caso, Juan Rene Muñoz Alarcón.

${ }^{49}$ REPÚBLICA DE CHILE. Central Nacional de Informaciones. CNI (R) N ${ }^{\circ}$ G - 203616. Anexo: Denuncia de Juan Rene Muñoz Alarcón. Santiago, 2 ago. 1978.
} 
Por vezes, os serviços de Inteligência brasileiros funcionavam como uma espécie de "moeda de troca", nos quais pessoas usariam de suas relações, devidas a seus cargos, para influenciar na tomada de decisões de terceiros, neste caso a aproximação entre os presidentes Hugo Banzer, da Bolívia, e Omar Torrijos, do Panamá. Tal situação se encontra no "Memorándum Secreto del General Sergio Arellano Starck para el Sr. General Don Augusto Pinochet Ugarte" de Santiago, 30 de março de 1976.

Arellano Starck inicia dizendo que viajou à Bolívia por "motivos particulares" de 21 a 28 de março de 1976, lá mantendo conversações com diversas autoridades, dentre elas o presidente Hugo Banzer Suárez. O general enumera os aspectos principais da conversa com Hugo Banzer, e um deles se centra no presidente panamenho Omar Torrijos Herrera. Arellano Starck relata que o general Banzer discorreu acerca da longa conversa que manteve com Torrijos quando da visita deste à Bolívia, salientando-lhe sobre a importância e conveniência de que o Panamá apoiasse o governo do Chile.

O general lembra Augusto Pinochet sobre a mensagem que Banzer enviou, em meados de novembro de 1975, sobre a organização de uma rede de boicote econômico ao Chile, que seria encabeçada por Cuba, informação esta que lhe foi passada por Torrijos, o qual, por sua vez, tomou conhecimento disto através do Reitor da Universidade do Panamá - um "Comunista", como salienta Arellano - que integrava a comitiva presidencial. Dizendo que agora Banzer "ampliou" esta informação, o general informa que Omar Torrijos desejaria que lhe entregassem o dirigente do Partido Comunista Luis Corvalán - "a quién los comunistas consideran un "Cardenal"” -, pois ele o "administraria" para diminuir a pressão internacional contra o Chile, tratando de garantir seu "possível silêncio" no exterior. Banzer estima que, dessa forma, o Chile poderia ganhar o apoio definitivo do Panamá. Por fim Arellano Starck explica que "Torrijos se ha acercado a Banzer porque este ha intercedido para que en Brasil le entrenen pilotos panamenhos. Además, ambos fueron simultáneamente Agregados Militares en EE.UU.". ${ }^{0}$

\footnotetext{
${ }^{50}$ REPÚBLICA DE CHILE. Junta de Gobierno. Secretaria General de Gobierno. Memorándum Secreto del General Sergio Arellano Starck para el Sr. General Don Augusto Pinochet 146 
A estrutura diplomática brasileira era estratégica para a coerção da ditadura sobre a comunidade de cidadãos asilados, estando o Centro de Informações no Exterior (CIEx), serviço secreto do Ministério das Relações Exteriores, responsável por ações de monitoramento, vigilância, espionagem, detenção e articulação repressiva dentro e principalmente fora do país. ${ }^{51}$

Inspirado na experiência do monitoramento do exílio brasileiro no Uruguai, o embaixador Pio Corrêa ${ }^{52}$ redigiu a portaria ultrassecreta que criava o CIEx, vinculado ao Serviço Nacional de Informações (SNI) e subordinado à Secretaria Geral de Relações Exteriores, em 1966, sendo que esse sistema de informações perdurou até 1985. Funcionando com o nome de "Assessoria de Documentação de Política Exterior", as atividades de espionagem funcionavam sob o nome de "Plano de Busca Externa", com apoio dos agentes do SNI e dos adidos militares - vinculados aos serviços de inteligência de suas Forças.

Esse órgão de espionagem ultrapassou o âmbito do Cone Sul, estendendo-se até a Europa, inclusive. Atuou nas embaixadas de Montevidéu, Buenos Aires, Santiago, Paris, Praga, Moscou e Lisboa (após a Revolução dos Cravos, em 1975). O grau de envolvimento com agências estrangeiras de informações foi intenso, principalmente com as do Cone Sul, havendo um amplo intercâmbio com órgãos de inteligência desses países. Constituiu-se em uma verdadeira "elite" do sistema de informação.

O CIEx teve como principal objetivo a espionagem, o controle e o monitoramento dos exilados brasileiros durante a ditadura. Nos locais onde havia a maior concentração de exilados, era exatamente onde o CIEx mais agia, conforme se apreende do informe no qual o órgão de inteligência necessita averiguar os brasileiros que estão se dirigindo para o Uruguai:

Ugarte. Santiago, 30 mar. 1976.

${ }^{51}$ FERNANDES, Ananda Simões. Quando o inimigo ultrapassa a fronteira: a conexão repressiva entre a ditadura civil-militar brasileira e o Uruguai (1964-1973). Dissertação (Mestrado em História). Porto Alegre: UFRGS, 2009.

${ }^{52}$ Manoel Pio Corrêa retirou-se do serviço diplomático no Uruguai no início de 1966, assumindo o cargo de Secretário Geral de Política Exterior, deslocando-se, em 1968, para a Embaixada brasileira em Buenos Aires. 
Índice: Concessão de salvo-conduto a asilado na Embaixada do Uruguai no Rio de Janeiro. Francisco Raimundo da Paixão.

Em 5/JAN/68, após a necessária autorização do Ministério da Justiça, o Ministério das Relações Exteriores concedeu o salvo-conduto $n^{\circ}$. 1/68 a FRANCISCO RAIMUNDO DA PAIXÃO, que se encontrava asilado na Embaixada do Uruguai no Rio de Janeiro desde 22/NOV/67. O marginado deverá seguir brevemente para Montevidéu, em avião da Força Aérea Brasileira. ${ }^{53}$

Desse modo, quando o Chile de Salvador Allende começou a ser o país de maior atração tanto dos exilados brasileiros que se encontravam em outros países, assim como dos integrantes da chamada segunda geração do exílio - composta principalmente por integrantes da luta armada e do movimento estudantil -, a atuação do CIEx passou a ser mais intensa nesse país.

Para obter as informações desejadas sobre os exilados, esse centro de espionagem recorria a vários métodos: infiltração de agentes no meio dos exilados, ${ }^{54}$ violação de correspondência, apreensão de materiais pessoais e das organizações, rastreamento de veículos considerados suspeitos que circulavam pela fronteira, controle das atividades e dos "pombos-correio", etc. Além disso, a contratação de informantes e, principalmente, a colaboração de forças policiais do país que abrigava os exilados era fundamental nas atividades exercidas pelo CIEx. Outro método de obtenção e de controle de informação era a violação de correspondência dos exilados, como se confirma no seguinte informe:

Índice: Asilados brasileiros no Chile e Uruguai. Francisco Raimundo da Paixão (Chicão).

\footnotetext{
${ }^{53}$ Arquivo do Ministério das Relações Exteriores do Brasil. Centro de Informações do Exterior. Informe n. 4.8 jan. 1968.

${ }^{54}$ Philip Agee relata que o comissário Alejandro Otero, do Departamento de Ligações e Investigações da polícia de Montevidéu, chegou a prender um sargento da Marinha que se passava por estudante entre os exilados brasileiros, a pedido do adido militar coronel Câmara Sena. Acusado de espionagem, foi posto em liberdade devido à intervenção da Embaixada brasileira. $\mathrm{O}$ adido militar recebeu assistência no desenvolvimento de operações para infiltração entre os exilados de um agente estadunidense da CIA situado na base de Montevidéu. Cf. AGEE, Philip. Dentro da "Companhia": diário da CIA. São Paulo: Círculo do Livro, 1976.
} 
FRANCISCO RAIMUNDO DA PAIXÃO (vulgo “Chicão") viajou em 24/FEV/68 de Montevidéu com destino a Santiago do Chile. Em MAR/68 o marginado enviou carta ao asilado brasileiro no Uruguai, ADÃO FAGUNDES DE AQUINO, na qual tecia severas críticas aos asilados radicados no Chile e, entre outras coisas, revela que a maioria recebe salários em dólares e se consideram da classe burguesa, não fazendo a menor questão de se interessar pelo socialismo autêntico. PAIXÃO conclui sua carta informando que viajará brevemente de Santiago com destino a um país comunista, possivelmente Cuba. ${ }^{55}$

É importante ressaltar que o CIEx não se envolvia diretamente em ações repressivas; ficava a seu encargo repassar as informações para o SNI, que depois as irradiavam para os órgãos de repressão.. Além do CIEx, o SNI era auxiliado nas atividades de espionagem pelos serviços de inteligência das Forças Armadas: o Centro de Informações do Exército (CIE), o Centro de Informações de Segurança da Aeronáutica (CISA) e o Centro de Informações da Marinha (CENIMAR). Já no âmbito civil, recebia ajuda na coleta de informações das diversas Divisões de Segurança e Informações (DSI) dos ministérios civis e da polícia política.

As Embaixadas brasileiras monitoravam não somente asilados brasileiros, mas também de outras nacionalidades, neste caso, chilenos, informando de suas condições a seu respectivo país, como se vê na PROVIDENCIA N ${ }^{\circ}$ 1272, enviada pelo Departamento Confidencial do Ministério do Interior, em 22 de março de 1976. Tendo como matéria "Asilados chilenos en México", Enrique Montero Marx, subsecretário do Interior, solicita que o documento que está em Anexo seja remetido para o Departamento de Extrangería y Migración, a fim de proibir o ingresso no país das pessoas assinaladas, que são em número de dez, dentre elas duas crianças, de cinco e sete anos de idade.

\section{REPÚBLICA DE CHILE \\ MINISTERIO DE RELACIONES EXTERIORES \\ DIRECCIÓN DE RELACIONES INTERNACIONALES \\ Departamento de América del Sur}

\footnotetext{
${ }^{55}$ Arquivo do Ministério das Relações Exteriores do Brasil. Centro de Informações do Exterior. Informe n. 151. 26 mar. 1968.
} 
RR. EE. (DIRELAS) RES. No 80

OBJ: Asilados chilenos en México

REF: Aide-Memoire de Embajada Brasil en Chile. - 16-mar-76.

Santiago, 16 de marzo de 1976.

DEL: Ministro de Relaciones Exteriores

AL: Señor Ministro del Interior

1. La Embajada de la República Federativa de Brasil en Chile ha tenido la deferencia de informar, por el documento de la Referencia, que el Gobierno de México ha concedido asilo a un grupo de ciudadanos chilenos que viajaron desde nuestro país al Puerto de Acapulco en el barco "Halcón Rojo II".

2. La Embajada de Brasil entrega el siguiente detalle de los asilados, haciendo presente que consultó a la Secretaría de Relaciones Exteriores de México, la que confirmó la concesión del asilo mencionado [...]. ${ }^{56}$

Por vezes, sabe-se da conexão repressiva de forma indireta, devido a trocas e vazamentos de informações, onde se vê a complexa rede estabelecida pelo Plan de Informaciones en el Exterior, do qual o Brasil faz parte. Tal é o caso do Ofício Reservado No 28, de 15 de fevereiro de 1977, no qual o Director General de Relaciones Exteriores envia para o Director de Inteligencia Nacional a transcrição do Telex No 037 que recebeu da Embaixada do Chile em Paris. Esta, por seu lado, obteve a informação - publicada no jornal "El Sol de México" - de uma Embaixada no México, sem especificar qual seja. O texto publicado no jornal, e remetido via Telex pela EmbaChile Francia, diz respeito ao Documento No 1975/107, timbrado como "República de Chile - Presidencia de la República - DINA”, e seria datado de 16 de setembro de 1975, conforme explica Jaime Lavin Fariña a Manuel Contreras. As informações transcritas são as seguintes:

En atención a lo convenido con Vuestra Excelencia, especifico razones por las que considero indispensable solicitar una partida adicional de seiscientos mil dólares en el presupuesto de esta Dirección para el año

\footnotetext{
${ }^{56}$ REPÚBLICA DE CHILE. Ministerio del Interior. Departamento Confidencial. Prov. ${ }^{\circ}$ 1272. Santiago, 22 mar. 1976. / Ministerio de Relaciones Exteriores. RR. EE. (DIRELAS) RES. No 80. Santiago, 16 mar. 1976. 
en curso [1975]: a) Aumento del personal de la Dina adscripto a las Misiones Diplomáticas de Chile, en total diez personas, dos en el Perú, dos en el Brasil, dos en Argentina, una en Venezuela, una en Cuesta Rica, una en Bélgica y una en Italia. b) Gastos adicionales para la neutralización de los principales adversarios de la Junta de Gobierno en el exterior, especialmente en México, Argentina, Cuesta Rica, Estados Unidos, Francia e Italia. c) Gastos relacionados con las operaciones en el Peru: ayuda a nuestros partidarios en la Armada Peruana y en la prensa, particularmente contribuciones a "Equis/X" y 'Opinión Libre". d) Asignaciones para oficiales de esta Dirección que siguen cursos preparatorios para grupos antiguerrilleros en centro de adiestramiento de la ciudad de Manaos, Brasil. ${ }^{57}$

As disputas políticas internas dos países também são alvo de monitoramento, visto a possibilidade de vazamentos de informações que comprometam o governo nacional, como ocorre no Ofício Reservado $\mathrm{N}^{0} 298$ de 09 de junho de 1978, enviado pelo Vice-Ministro de Relações Exteriores - Enrique Valdes Puga - para o Ministro do Interior Sergio Fernandez Fernandez, tendo como Objeto: "Solicita análisis sobre correspondencia Jefe SNI, remitida por Oficio que indica".

Como informa a Embaixada do Chile em Brasília, a publicação de correspondência atribuída ao Chefe do Serviço Nacional de Inteligência, general João Batista Figueiredo, teve grande repercussão no Brasil. O vice-ministro informa que as estimativas feitas são as de que isto constitua uma manobra política destinada a prejudicar a indicação de Figueiredo à presidência no Brasil, pretendendo, também, comprometer o próprio presidente Ernesto Geisel. No entanto, considera "que se lleve a cabo un análisis de la referida situación, dado que en la correspondencia del SNI hecha pública en Brasil, aparece mencionada la ex-Dina y otras autoridades de nuestro Gobierno". 58

\footnotetext{
${ }^{57}$ REPÚBLICA DE CHILE. Ministerio de Relaciones Exteriores. RR. EE. (DIGEN) RES. $\mathrm{N}^{\mathrm{o}} 28$. Santiago, 15 feb. 1977.

${ }^{58}$ REPÚBLICA DE CHILE. Ministerio de Relaciones Exteriores. RR. EE. (DIGEN) RES. $N^{\text {o } 298 . ~ S a n t i a g o, ~} 9$ jun. 1978.
} 


\section{Considerações finais}

Durante os seus "anos de chumbo", a ditadura brasileira, incorporando a experiência repressiva adquirida no combate à oposição interna, intensificou a sua política de desestabilização ao governo de Salvador Allende. A preocupação brasileira com o Chile, entretanto, não se restringia somente ao monitoramento das atividades dos exilados presentes nesse país: a luta armada e, principalmente, a Unidad Popular passaram a ser seus alvos.

O Brasil participou ativamente do golpe de setembro de 1973, e imediatamente passou a colaborar com a nascente ditadura chilena. Assim, a conexão repressiva entre os dois países foi estabelecida, levando à perseguição, sequestro, tortura, assassinato e inclusive desparecimento de militantes.

Apesar de o Chile ter o protagonismo na Operação Condor e de o Brasil ter participado desse plano como observador, o papel dos agentes brasileiros não foi secundário. Quando necessário, a ditadura brasileira apoiou e colaborou com as ações promovidas no marco dessa operação, como demonstra a documentação dos órgãos diplomáticos - peça-chave na conexão repressiva entre os países do Cone Sul. 